\title{
SPEED OF MEAN REVERSION: AN EMPIRICAL ANALYSIS OF KSE, LSE AND ISE INDICES
}

\author{
Rana Imroze PALWASHA ${ }^{1}$, Nawaz AHMAD ${ }^{2}$, Rizwan Raheem AHMED ${ }^{3}$, \\ Jolita VVEINHARDT ${ }^{4}$, Dalia ŠTREIMIKIENE ${ }^{5^{*}}$ \\ ${ }^{1}$ Shaheed Zulfikar Ali Bhutto Institute of Science \& Technology, 90-Clifton, Karachi, Pakistan \\ ${ }^{2}$ Institute of Business Management (IoBM), Creek Road-75190, Karachi, Pakistan \\ ${ }^{3}$ Faculty of Management Sciences, Indus University, Block-17, Gulshan, Karachi-75500, Pakistan \\ ${ }^{4,5}$ Institute of Sport Science and Innovations, Lithuanian Sports University, \\ Sporto g. 6, LT-4422 Kaunas, Lithuania
}

Received 23 January 2017; accepted 11 June 2017

\begin{abstract}
The purpose of this study is to determine the presence of mean reversion in the stock markets indices of Pakistan, moreover, to measure, and compare the speed of mean reversion of the stock markets indices across Pakistan. In order to carry out the research study, the daily data of three stock indices of Pakistan such as: KSE-100, LSE-25 and ISE-10 are collected from 2003 to 2014. After the application of tests such as ARCH and GARCH, it was found that returns series of KSE-100, LSE-25 and ISE-10 indices exhibit mean reversion, indicating that the returns revert back to their historical value after reaching an extreme value. Further, the mean reversion rate shows that KSE100 index has the slowest mean reversion, however, the ISE-10 index has the fastest mean reversion among the three indices. Therefore, the results of the study concluded that KSE-100 index, due to the slowest mean reversion rate has higher volatility over a longer period of time. On the contrary, since, ISE-10 index has exhibited the fastest mean reversion with the lowest volatility as compared to others. But due to fast mean reversion rate, it will help investors to gain profits over a shorter period of time. Thus, it can be recommended that the investor willing to bear the risk of time and looking for long-term investment should invest in KSE-100 index. However, investors looking for higher profits in a shorter period can invest in the ISE-10 index but with higher risk-returns trade-off.
\end{abstract}

Keywords: Mean reversion, stock indices, ARCH \& GARCH, KSE100, LSE25, ISE10.

JEL Classification: C32, G1, G12, G14.

\section{Introduction}

Background of the study. Since the 1970s, one of the frameworks for the asset-pricing model has become a central proposition for the market prices. This proposition, which was considered as the core of finance, is known as the efficient market hypothesis. According to this

*Corresponding author. E-mail: dalia.streimikiene@lsu.lt

(C) 2018 The Author(s). Published by VGTU Press

This is an Open Access article distributed under the terms of the Creative Commons Attribution License (http://creativecommons. org/licenses/by/4.0/), which permits unrestricted use, distribution, and reproduction in any medium, provided the original author and source are credited. 
hypothesis, all the information that one individual could need regarding a firm is available in the prices, thus exerting no possibility for any individual to gain excess return. However, many investors believe that if focused properly on securities, which generally underperformed but better returns in the future could be identified. Therefore, these investors use various techniques' that help them for identifying these undervalued stocks. However, according to efficient market hypothesis also known as the random walk, it is impossible to identify the securities that can outperform (e.g., Zakamulin 2016; Wang et al. 2015; Kühnlenz 2014; etc.).

Contradicting to the efficient market hypothesis or random walk, another phenomenon that explains the belief of investor is the theory of mean reversion. According to mean reversion, prices rates after reaching extreme value all return back to their mean values (e.g., Chi et al. 2016; Lubnau, Todorova 2015; Henderson 2004; etc.). Thus, a variable is said to be exhibited mean reversion behavior, if it has the tendency to revert back to its long-term average value over the period. Therefore, referring exhibiting mean reversion synonymous with showing long-term average returns (e.g., Chaves, Viswanathan 2016; Boussaidi, Kouki 2015; Huggins, Schaller 2013; etc.). Similarly, Hillebrand (2003) explains mean reversion as changes in the market returns or prices following a direction that is exhibiting a reversion level, which is observed in reaction to previous changes made. For instance, if the market returns showed positive change then mean reversion will cause the market returns to exhibit negative change or vice versa. From the point of view of investors, this means that prices can be predicted on the basis of their historical behavior.

The differences between the random walk and mean reversion. The difference between the random walk and mean reversion can be captured with the help of graphical explanation. Both Figure 1 and Figure 2 have the model sequence of observations, which are ordered in time, starting with a beginning value of zero. Figure 1 indicates random walk with drift where mean of every observation is the value of the previous observation making the process of random walk a fair game where the knowledge of historical events never help one to predict the mean of the future winnings.

On the contrary, Figure 2 indicates mean reversion where the mean of every observation exhibits the tendency of returning back to its mean value.

Explanation of mean reversion. Working on the proposition that decisions of investors cannot be categorized as rational, therefore, researchers developed one of the famous anomalies of finance known as mean reversion. It can be said that mean reversion is a by-product of aversion to losses, availability bias and lastly affinity for the lower prices (e.g., Tie, Zhang 2016; Oikarinen, Schindler 2015; Bhave, Libertini 2013; etc.). The first factor that contributes to the development of mean reversion is availability bias. Availability bias shows that people base their decision towards information, but that is easily recallable to them. As it is difficult to recall information from experience, therefore, people give more weightage to new information (Gimpel 2007). Thus, explaining this high weightage of current news, and events by investors, as one of the reasons of an overreaction of a stock price.

In addition, the availability bias, another factor contributing in mean reversion development is an aversion of loss. After the bad news of loss passes to investors, the investors prefer to hold the stocks, thus become loss averse. As the time passes, and the information is completely digested by the investors, the prices return to values causing underperformed stocks to 


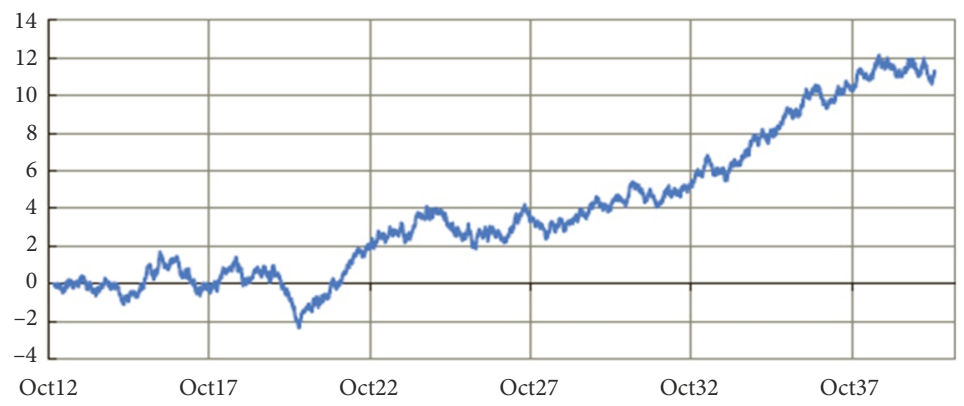

Figure 1. Random walk (source: Huggins and Schaller 2013:19)

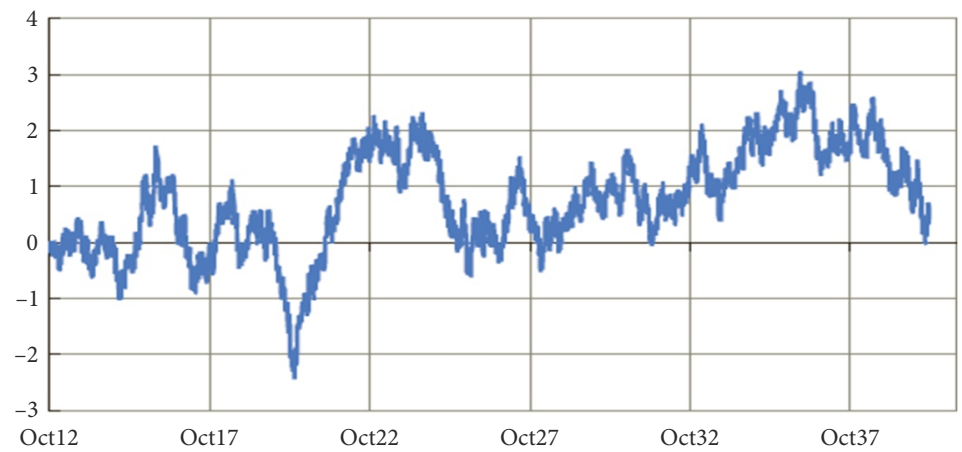

Figure 2. Mean reversion process (source: Huggins and Schaller 2013:19)

outperform. Lastly, the attractiveness of lower prices also contributes to mean reversion. As according to researchers, the people are more satisfied with buying stocks at a lower prices as compared to higher prices, causing underperforming stocks to be bought more as compared to outperforming stocks leading to mean reversion (e.g., Tsekrekos, Yannacopoulos 2016; Hart et al. 2015; Annaert, Hyfte 2005; etc.).

Thus, concluding that the fad of the above-described market psychology along with the noise trading cause investors to develop the belief that they own information based on which future returns prediction can be made, therefore, resulting in the development of predictable patterns in the returns (Annaert, Hyfte 2005).

Problem statement and objective. The aim of the study is to determine the presence of mean reversion in stock markets indices of Pakistan. Further, measure and compare the speed of mean reversion of Pakistani stock markets indices. Therefore, specifically the study intent to accomplish the given below objectives:

- Determine the existence of mean reversion in stock markets indices of Pakistan.

- Measure the speed of mean reversion of the stock markets indices of Pakistan.

- Compare the pace of mean reversion of the three stock markets indices of Pakistan.

By accomplishing the above specified objective the study intent to help investors to identify the rate with which the prices revert back to their mean value, which will not only help them in the selection of strategies to be used but also plan their entry and exit in the trade. 
At the same time, it will help government policy makers, whether to use intervention policies in the stock market or not.

The debate of mean reversion has been going since the 1970s. As the literature gave both evidence in support and against of mean reversion (e.g., Chen, Hsu 2016; Oikarinen, Schindler 2015; Hart et al. 2015; Annaert, Hyfte 2005; Borges 2011; Chaudhuri, Wu 2003; Lock 2007; Hakim, Neaime 2003; Yilanci 2012; Chen et al. 2012; etc.). However, the literature fails to provide enough evidence of mean reversion in stock markets indices of Pakistan. Therefore, the study is proposed to investigate the speed of mean reversion in stock markets indices of Pakistan namely KSE-100 index, LSE-25 index, and ISE-10 index.

The significance of this research. Now, KSE100 has been included in the emerging markets, and for last few years there is a tremendous growth in KSE100 index, and now crossed the 50000-index milestone. Thus, this phenomenal growth in KSE100 distinguishes it from other regional and emerging markets. Now, the foreign investors are more attracted towards the Pakistan stock exchange, even Chinese investors have stepped in the market and they intend to buy $40 \%$ share of the KSE100. Hence, it will further enhance the significance of this market. Therefore, this research will be valuable for existing and potential local and foreign investors, and this study also provides the basic foil to the financial experts and researchers around the globe.

Hypotheses. On the basis of overall discussion, objectives of our research, and previous literature following three hypotheses have been developed:

$H_{1}$ : The stock returns of KSE 100, LSE 25 and ISE 10 indices exhibit ARCH effect.

$\mathrm{H}_{2}$ : The stock returns of KSE 100, LSE 25 and ISE 10 indices exhibit GARCH effect.

$\mathrm{H}_{3}$ : Market returns of KSE100, LSE25, and ISE10 indices observe mean reversion.

\section{Literature review}

Financial researchers all around the world are in search of theories that could help them to predict the stock behavior. One of the oldest propositions is efficient market hypothesis, according to which, stock prices reflect all the information about the organization one need to know regarding investment, since, these do not follow any patterns, therefore, could not be predicted; making it likely that these can move upwards or downwards irrespective of their past performance. However, the assumption that stock returns are unpredictable was no longer certain (Dupernex 2007) after what was observed in 2007. During this period there was a quick movement observed in falling of stock markets. Different markets such as energies, metals, sold dramatically by the investors and funds to be liquidated, thus creating a panic in the financial world. Further, after careful analysis the blame for drastic crises was put on the policies that were created by the financial system (e.g., İzgi, Duran 2016; Neaime 2015; Shaffer 2010; etc.). Making different econometricians, and financial practitioners from all around the world to question that is the foundation of the whole system based on a false assumption of efficient market hypothesis (e.g., Mtunya et al. 2016; García et al. 2015; Malkiel 2003; etc.).

Thus, the growth of discontentment with this theory causes researchers to work on other theories that could help them to explain the market phenomenon. The proposition that was suggested in financial economics by keeping in view the idea that "what goes up must come 
down", this theory when referring to stock returns commonly known as mean reversion. Mean reversion can be referred to as the tendency of the market returns to come back to historic values pulled by a gravitational force. DeBondt and Thaler (1985) first gave evidence of mean reversion in stock returns, they showed that stock returns that were initially categorized as losses for a period of 3 to 5 years, were able to help their holders earn high returns after the period of three years. Another study indicated the evidence of mean reversion was carried out by Fama and French (1988), by running the regression of return over a period of time on it lags, they found the existence of a memory pattern with the market prices. Further, by showing that the past prices are able to predict the future, indicating the presence of memory pattern, which supported mean reversion. The mean reversion is divided into short term and long term mean reversion (e.g., Chi et al. 2016; Hart et al. 2015; Lim 2011; etc.).

The reversion of stock prices to their mean value just after a month of portfolio formation is referred as short-term mean reversion. As discussed earlier where DeBondt and Thaler (1985) were the first one, worked on mean reversion by using annual data from the New York stock exchange and proved that reversion took place in 3 years. However, close examination of their research revealed the existence of short-term mean reversion. As the winning stock underperforms by $8 \%$, whereas, the losing stock outperform by $-2.10 \%$. Earlier short-term mean reversion was not attractive to investors, the reason for such behavior includes the high cost associated with transactions and data. Later, due to the presence of technology as things become simpler, thus, there was an increase in the focus of studies towards short-term mean reversion (Bhave, Libertini 2013). Further, as the investors need to get information daily basis regarding the investment results, thus, by studying short-term mean reversion proved to be more attractive as compare to the long-term mean reversion (e.g., Tie, Zhang 2016; Wang et al. 2015; etc.).

If the winning stock underperforms in the market, whereas, the losing stock outperform in the market after the period of one year then such mean reversion is termed as long-term. The examination of the literature review for the long-term mean reversion indicates the presence of two different methods, which were used for the testing of stationarity such as absolute mean reversion and relative mean reversion.

Mean reversion in stock prices. This debate of, whether the returns of one market is belonged to random walk or mean reversion, this caught the attention of all researchers due to its importance from all over the World. The reason being, if the process of mean reversion is adopted by the stock prices then it will make investors to better predict the future by using the information about past returns. For instance, according to Tsekrekos and Yannacopoulos (2016), Chaves and Viswanathan (2016), Lubnau and Todorova (2015), Hart et al. (2015), Balvers et al. (2000), if the stock returns are mean reversed then they can help investors to make more profit through contrarian trading strategy, in which people buy stocks when they perform poor and sell them when their performance become good. Working on the same area Neaime (2015), Hakim and Neaime (2003) found the existence of mean reversion in the MENA countries, specifically Egypt, Jordan, Morocco and Turkey, and pointed out the existence of high speed of mean reversion, which can cause the volatility in the stock markets to decrease or vice-versa through Monte Carlo simulation technique. This reduction in the volatility will, in turn, cause the stock prices to increase. Similarly, like others, highlighted the 
importance by Poterba and Summers (1987), and pointed out the existence of mean reversion, which explains many behaviours of the market, such as, most of the universities refer to markets' past trend line while making decision of investment in endowments, similarly, many financial practitioners believe that the stock prices are estimated incorrectly, thus, it is better not to base their investment decisions on the current market prices.

By realizing the importance of the theory, whether the stock prices follow mean reversion or random walk, researcher are trying to explore this area for past few years. Among them, Kim et al. (2001) tried to prove that the movements created in the stock markets because of the behavioral response of investors towards the changes in the market volatility actually creates mean reversion. However, the implication of time-varying estimates made them reject the hypothesis, which was concluding that mean reversions are not produced due to behavioral responses of investors. Similarly, Balsara et al. (2007) while evaluating Shanghai and Shenzhen markets found that these markets fail to follow random walk, further found their study to support the findings of Lal et al. (2016), Wang et al. (2015), Balvers et al. (2000), according to which, if stocks follow mean reversion theory then investors are likely to get profit from contrarian strategy.

As in the study of Balsara et al. (2007), the investor was also able to generate positive returns by using contrarian strategy. Manzana (2007) has observed the same reversion phenomenon in S\&P500 stock index. Extending the work of Manzana (2007) on the US stock markets Serletis and Rosenberg (2009) took four market indices namely Dow Jones, S\&P 500, NYSE and NASDAQ composite index, for the investigation of weak form of hypothesis, and found the results to provide evidence against weak form of hypothesis, due to the display of anti-persistence in the stock returns. Apart from the research studies discussed above, which explored the phenomenon of mean reversion in the market of developed world, there are also research studies that explore the existence of mean reversion in emerging markets such as, Chaudhuri and $\mathrm{Wu}$ (2003) took seventeen emerging markets and found their study that was in favor of the theory of mean reversion. Apart from just finding mean reversion they also attempted to calculate mean reversion rate with the help of Half-life method and concluded that the stock prices of emerging markets revert back to their historical values after a period of 30 months. In addition, they presented an argument regarding some past studies for the failure to prove the existence of mean reversion, because of the ignorance of structural break in their studies.

Thus, mean reversion in the studies could be detected if they account structural breaks. Poshakwale (2003) was also among those who rejected the hypothesis of the random walk and proved the existence of mean reversion on the stock markets of India. Likewise, Malliaropulos and Priestley (1996) studied mean reversion in the South Asian markets. Through their study not only contributed to existing literature by supporting mean reversion but also added by testing of mean reversion, the returns should be adjusted according to their time variations. In addition to above studies, few researchers have tried to found the existence of mean reversion in Karachi stock exchange also. These researchers include Lal et al. (2016), Vveinhardt et al. (2016), Riaz (2014), Mustafa and Ahmed (2013) found that Karachi stock exchange also exhibits mean reversion process. 
On the contrary, there are also some research studies that give contradicting results, such as: Lo and McKinlay (1988) while studying mean reversion in the United States markets provide the evidence against mean reversion. Supporting their work Kim et al. (1991) found that the same mean reversion pattern in stock markets before the U.S war. Similarly, Narayan, P. K. and Narayan, S. (2007) using five different panel unit root test tried to evaluate the existence of mean reversion in the stock market and concluded that there is no existence of mean reversion in the stock prices. Thus, this supported the old random walk theory to still exist. Apart from the above literature, some other important researches have been carried out by Borges (2011), Okpara (2010), Lock (2007), Narayan, P. K. and Narayan, S. (2007); Narayan and Smyth (2006), Urrutia (1995) found that the Taiwan, Nigerian Portuguese, Latin American and 22 OECD countries stock markets follow the random walk.

However, as seen above due to contradicting conclusions of different researches it has not been clear yet that where the stock returns exhibited a random walk or mean reversion. As some research studies have pointed out that mean reversion in some countries' stock markets, whereas, at the same time same countries' stock indices have provided strong evidence of random walk. It is further concluded that the existence of mean reversion in particular country varies from country to country or region to region. Moreover, as highlighted in the literature the few studies conducted on this topic for the Karachi stock exchange index, which has demonstrated the existence of mean reversion (e.g., Lal et al. 2016; Vveinhardt et al. 2016; etc.). Therefore, this study aims to contribute to the literature by identifying the presence of mean reversion in other stock exchange indices along with determining and comparing the pace of mean reversion of the stock markets indices of Pakistan.

The implication of mean reversion. The first step of investment is asset allocation; this allocation of investment requires investors to invest their money in stocks, funds of different markets, companies, and sectors. As it helps the investors to sell off some of their investments that has not been profitable while retaining those that are giving them good yields. The only reason to work this, if someone believes that, the market will return to its historical values. The presence of mean reversion has certain implications that are discussed below.

The first implication of mean reversion is that, as the prices do not reflect fundamental values, this cause stock market not to direct funds to their best usage. For instance, a trader may be driving the stock prices of companies high, which have low fundamental value. On the other hand, those companies, which have high fundamental value, may be driven low. This causes companies, who have low fundamental values to raise capital easily as compared to companies with high fundamental values (e.g., Zakamulin 2016; Vveinhardt et al. 2016; Engle, Morris 1991; etc.).

The second implication of mean reversion is that it causes the prices of different rate of return that are possible for an asset to vary. For instance, suppose that from 1 to 5 periods the average return on a stock is $10 \%$, later an increase in prices above their fundamental values was observed up to $30 \%$. However, when prices fall back to their fundamental values, their return was only $4 \%$. This showed that if their returns that are greater than the average then they will be followed by returns that are lower than the average (e.g., Mtunya et al. 2016; Oikarinen, Schindler 2015; Engle, Morris 1991; etc.). 
Last possible implication of mean reversion is the extreme volatility of prices in short run. Although stock prices are volatile in the efficient market but this volatility increases when considering mean reversion. The reason for this excessive volatility is that the new information causes the prices to change more than of their values. On the contrary, excessive volatility is not observed in the case of a long run as the prices revert to their historical prices. Thus, considering long run it leads to the conclusion that, changes in prices in long run is same for both efficient markets and mean reversion (e.g., İzgi, Duran 2016; García et al. 2015; Engle, Morris 1991; etc.). These implications have caused mean reversion to prove itself as a successful method of trading and investing for the financial practitioners by developing various strategies such as contrarian and statistical arbitrage.

\section{Data and methodology}

Using a positivist approach that revolves around the scientific inquiry in which we construct three hypotheses and analyze the results by using econometric techniques. The research intends to verify the propositions made in this study regarding the speed of mean reversion. The empirical verification of these claims, which made the results generalizable, indicates that deductive approach is used in the research. Apart from following deductive approach, the study is quantitative and descriptive in nature. Further, to substantiate the aim of the study, which has time series data covering the period from 2003 to 2014 for daily returns of KSE 100 index; LSE 25 index and ISE-10 index. The data of these indices have been obtained from the official websites of the Karachi stock exchange, Lahore stock exchange, and Islamabad stock exchange. From the data dependent variable, which represents the current period, returns and independent variable acting as lagged returns for the ' $k$ ' period are generated.

Estimation models. As evident from the literature review that there are numerous research studies, which have employed ADF model for the stationarity and ARCH \& GARCH models for testing of mean reversion that include Zakamulin (2016), Tie and Zhang (2016), Balvers et al. (2000), Balsara et al. (2007), Poshakwale (2003), Manzana (2007), Narayan, P. K. and Narayan, S. (2007), Saeedi et al. (2012) etc. There are also other researchers who have employed ARCH and GARCH models such as, Bali and Demirtas (2008), Goudarzi (2013); therefore, both the model has been applied for detection of mean reversion in this research. The Half-life model has also been used to determine the speed of mean reversion for all three indices in undertaken study.

Augmented Dickey-Fuller model. Before testing whether the returns series of KSE, LSE and ISE exhibit mean reversion or not, the unit root is tested through application of Augmented Dickey-Fuller (1981) test to determine the stationarity of the data, which was developed by Dickey and Fuller (1979) and further, refined in 1981. In other words, this test helped in the determination of whether the series contain unit root or not. If the series show that there is no unit root in the data, and then this indicates stationary series $\mathrm{I}(0)$, in other words, the returns exhibit mean reversion. The equation of the model can be expressed as follows:

$$
\Delta y_{t}=\alpha_{o}+\alpha_{1} y_{t-1}+\sum_{i=1}^{n} \alpha \Delta y_{t}+e_{t},
$$

where: $y_{t}-$ the return series, and $e_{t}-$ the white noise term. 
$\operatorname{ARCH}(q)$ model. If the application of ARCH model shows that $\operatorname{Var}(\mu t)=\alpha^{2} t$, it indicates that there is no ARCH effect, no heteroscedasticity or presence of time varying ability in the data. On the other hand, if $\operatorname{Var}(\mu \mathrm{t}) \neq \alpha^{2} t$, then it shows that variance of error depends upon lagged of square error term indicating ARCH effect. The generalized form of $\mathrm{ARCH}(\mathrm{q})$ model can be written as follows:

$$
\sigma_{t}^{2}=\alpha_{0}+\sum_{i=1}^{q} \alpha_{j} \varepsilon_{t-j}^{2},
$$

where: $\sigma_{t}^{2}$ - the conditional error variance, and $q$ is lags of the squared errors.

$\operatorname{GARCH}(\boldsymbol{p}, \boldsymbol{q})$ model. In addition to $\mathrm{ADF}$ and $\mathrm{ARCH}$, a natural extension of $\mathrm{ARCH}$ is known as the generalized ARCH model, which is also applied to test mean reversion, as it helps overcome some of the problems of ARCH model. In GARCH model, the ARCH term $(\alpha)$ and GARCH term $(\beta)$ are sums together. If the sum of both terms is less than $1(\alpha+\beta$ $<1)$ then the return series exhibit mean reversion and if the sum is equal to $1(\alpha+\beta=1)$ then the series follow the random walk. The generalized equation for GARCH (p, q) model can be expressed as follows:

$$
\sigma_{t}^{2}=\omega+\sum_{i=1}^{q} \alpha_{i} \varepsilon_{t-i}^{2}+\sum_{j=1}^{p} \beta_{j} \sigma_{t-j}^{2},
$$

where: $\sigma_{t}^{2}$ - the conditional variance, which is a function of its own past, as well as squares of past residuals. In the interest of parsimony, GARCH $(1,1)$ model would be fitted for conditional variance as developed by Engle (2001).

Half-Life model. From the application of ARCH and GARCH models as discussed above, are being used to test that the returns exhibit mean reversion, then next step will involve the calculation of the speed of mean reversion, which will be done through the application of half-life method. The half-life method will help to calculate the period that it takes the returns to move half the distance of the long-term average values of KSE, LSE and ISE indices. The numeric values representing the speed of mean reversion of these three stock indices, and then these markets can be compared, to determine which stock exchange index shows faster mean reversion as compared to others. The half-life model is given as follows:

$$
H L=1-\frac{\log (2)}{\log (\lambda)},
$$

where: $\lambda$ - the sum of ARCH and GARCH parameters, which are included in the GARCH model.

\section{Results and findings}

Descriptive analysis. Table 1 shows that the KSE-100 index returns; the mean value is 0.0816 , whereas for the LSE-25 index returns and ISE-10 index returns the average value of returns are 0.0421 and 0.050 respectively. In addition to the mean, the standard deviation value indicates that on an average the KSE-100 index returns deviate from its mean value by 1.347 , whereas returns of the LSE-25 index and ISE-10 index deviate from its mean value by 1.752 and 1.861 respectively. 
Apart from mean and standard deviation, the value of skewness and kurtosis depicted about the symmetry of return series. Specifically, negative skewness value of KSE-100 index returns and LSE-25 index returns indicate that the left tail of the return series is long. On the contrary, ISE-10 index returns have a positive skewness value, which means that the right tail is long as compared to the left. Further, the kurtosis value is greater than 3, indicating all the three return series are leptokurtic. In other words, the return series have a higher peak and longer tail. Furthermore, Jarque-Bera indicates the distribution of the return series. As all the three returns series have a probability of less than 0.05 , thus, rejecting the null hypothesis of the normal distribution, concluding that all three series are not normally distributed.

Stationary in the stock markets indices. In order to determine that stationarity of the series, unit root test was applied on the returns of three stock indices of KSE-100 index, ISE-25 index and LSE-25 index. As the Table 2 shows that absolute value of augmented dickey-fuller test statistics is greater than the absolute critical value, thus, it demonstrated that the returns of all the three indices are stationary or in other words, they do not have a unit root. This absence of unit root will cause the series to follow the standard assumption for the asymptotic distribution.

ARCH Effect in stock markets indices. After establishing the stationarity of the series, the next step is to satisfy the ARCH effect, which is the precondition for running an $\mathrm{ARCH}$ and GARCH model, for this purpose, ARCH-LM test was used. Table 3 shows that p-value of three returns series (KSE-100 index, LSE-25 index, and ISE-10 index) are less than 0.01 $(\mathrm{p}<0.01)$ for ARCH-LM test. This concluded the rejection of the null hypothesis, and thus established that there is a significant ARCH effect. Hence, this also satisfied the precondition and qualifying the series for application of an ARCH and GARCH models.

Mean reversion in the stock indices. Results of Table 4 show that since GARCH $(1,1)$ is used, as it captures an infinite ARCH order process. Further, a high order of ARCH model indicates that high degree of freedom is consumed, thus it is better to estimate GARCH Model. In Table 4 RESID $(-1)^{\wedge} 2$ also known as ARCH term that represents the previous period squared residuals, whereas, GARCH (-1) known as GARCH term, which represents the previous day squared variance.

Table 4 also shows that both ARCH term (RESID $(-1)^{\wedge} 2$ and GARCH term GARCH $(-1)$ is significant under student $\mathrm{T}$ distribution with fixed difference, as the p-value of both is less than $0.01(\mathrm{p}<0.01)$ for the returns of all three stock markets indices such as, KSE-100 index, LSE-25 index and ISE-10 index. Thus, the null hypotheses have been rejected for the ARCH and GARCH effects, therefore, it is concluded that both ARCH and GARCH have statistically significant effects. Having both ARCH and GARCH significant effects led to the conclusion that previous day information influences the current volatility of KSE-100 index return series, LSE-25 index returns, and ISE-10 index returns. Furthermore, the value of R-square, which indicates that internal shocks represented by $\mathrm{ARCH}$ and $\mathrm{GARCH}$ coefficients explain only $1.385 \%, 0.767 \%$ and $0.533 \%$ variation in KSE- 100 index, LSE-25 index and ISE-10 index returns respectively and leaving $98.61 \%, 99.24 \%$ and $99.47 \%$ variation unexplained.

Lastly, Table 4, summing ARCH and GARCH coefficients for the identification of mean reversion. According to Bollerslev (1986), the series are stationary or mean reverting if the sum of both coefficients is less than $1(\alpha+\beta<1)$. Thus, Table 4 indicates that returns series of KSE-100 index, LSE-25 index, and ISE-25 index show a mean reversion, which means 
Table 1. Summarization of descriptive statistics (source: authors' estimation)

\begin{tabular}{|l|c|c|c|}
\hline \multicolumn{1}{|c|}{ Statistics } & KSE-100 Index Returns & LSE-25 Index Returns & ISE-10 Index Returns \\
\hline Mean & 0.081638 & 0.042143 & 0.050023 \\
\hline Median & 0.12951 & 0.04974 & 0.000000 \\
\hline Maximum & 8.254687 & 9.298555 & 20.6641 \\
\hline Minimum & -6.041752 & -7.594632 & -11.0722 \\
\hline Standard Deviation & 1.347126 & 1.751784 & 1.861027 \\
\hline Skewness & -0.404312 & -0.307328 & 1.12879 \\
\hline Kurtosis & 5.777392 & 5.085898 & 25.95755 \\
\hline Jarque Bera & 1032.375 & 583.5151 & 26917.71 \\
\hline Probability & 0.0000000 & 0.00000 & 0.000000 \\
\hline
\end{tabular}

Table 2. Stationary in stock markets indices (source: authors' estimation)

\begin{tabular}{|l|c|}
\hline \multicolumn{1}{|c|}{ Index } & ADF Statistics \\
\hline KSE-100 Index Return & -47.49266 \\
\hline LSE-25 Index Return & -48.78746 \\
\hline ISE-10 Index Return & -28.03567 \\
\hline
\end{tabular}

Note: MacKinnon (1996) critical values are $-3.432369,-3.43237$ and -3.435532 at $1 \%$ level, $-2.862318,-2.862318,-2.863716$ at $5 \%$ level and $-2.567228,-2.567228$ and -2.567979 at $10 \%$ level respectively.

Table 3. ARCH effect in stock markets indices (source: authors' estimation)

\begin{tabular}{|l|c|c|c|}
\hline \multicolumn{1}{|c|}{ Statistics } & KSE-100 Index Returns & LSE-25 Index Returns & ISE-10 Index Returns \\
\hline F - Statistics & 343.1780 & 304.7362 & 49.80461 \\
\hline Probability & 0.000000 & 0.000000 & 0.000000 \\
\hline
\end{tabular}

Table 4. Mean reversion in stock indices (source: authors' estimation)

\begin{tabular}{|c|c|c|c|c|c|c|c|c|}
\hline \multirow[b]{2}{*}{ Index } & \multirow{2}{*}{$\begin{array}{c}\text { GARCH } \\
(1,1)\end{array}$} & \multicolumn{2}{|c|}{ Mean Equation } & \multicolumn{3}{|c|}{ Variance Equation } & \multirow[b]{2}{*}{$\mathrm{R}^{2}$} & \multirow[b]{2}{*}{$\alpha+\beta$} \\
\hline & & Constant & $\begin{array}{c}\text { Return } \\
(-1)\end{array}$ & Constant & $\begin{array}{l}\text { RESID } \\
(-1)^{\wedge} 2\end{array}$ & $\begin{array}{c}\text { GARCH } \\
(-1)\end{array}$ & & \\
\hline \multirow{4}{*}{$\begin{array}{l}\text { KSE-100 } \\
\text { Index }\end{array}$} & Coefficient & 0.146394 & 0.096399 & 0.040058 & 0.195924 & 0.787942 & \multirow{4}{*}{0.01385} & \multirow{4}{*}{0.9838} \\
\hline & Std. Error & 0.016436 & 0.019467 & 0.006236 & 0.01782 & 0.015263 & & \\
\hline & Z-Statistic & 8.90717 & 4.951913 & 6.423163 & 10.99447 & 51.62349 & & \\
\hline & Prob & 0.0000 & 0.0000 & 0.0000 & 0.0000 & 0.0000 & & \\
\hline \multirow{4}{*}{$\begin{array}{l}\text { LSE-25 } \\
\text { Index }\end{array}$} & Coefficient & 0.110899 & 0.059303 & 0.096485 & 0.186505 & 0.785682 & \multirow{4}{*}{0.00767} & \multirow{4}{*}{0.9721} \\
\hline & Std. Error & 0.023525 & 0.019586 & 0.015087 & 0.018212 & 0.016993 & & \\
\hline & Z-Statistic & 4.714018 & 3.027888 & 6.395227 & 10.24081 & 46.23685 & & \\
\hline & Prob & 0.0000 & 0.0025 & 0.0000 & 0.0000 & 0.0000 & & \\
\hline \multirow{4}{*}{$\begin{array}{l}\text { ISE-10 } \\
\text { Index }\end{array}$} & Coefficient & 0.058999 & -0.01414 & 0.442934 & 0.204817 & 0.51612 & \multirow{4}{*}{0.00533} & \multirow{4}{*}{0.7209} \\
\hline & Std. Error & 0.034401 & 0.035268 & 0.050923 & 0.028253 & 0.039356 & & \\
\hline & Z-Statistic & 1.715055 & -0.40089 & 8.698062 & 7.249491 & 13.1142 & & \\
\hline & Prob & 0.0863 & 0.6885 & 0.0000 & 0.0000 & 0.0000 & & \\
\hline
\end{tabular}


that stock prices revert back to their historical values. This existence of mean reversion in all the three returns series support the studies of Vveinhardt et al. (2016), Chaudhuri and Wu (2003), Riaz (2014), Poterba and Summers (1987), Malliaropulos and Priestley (1996), Mustafa and Ahmed (2013), Balvers et al. (2000), Annaert and Hyfte (2005) etc.

The speed of mean reversion in the stock indices. Table 5 shows the speed of mean reversion in the stock indices of Pakistan. The rule of thumb applied here is, the higher the sum of ARCH coefficient ( $\alpha)$ and GARCH coefficient $(\beta)$, higher will be the volatility, and slower will be the speed of mean reversion. As KSE-100 index has the highest sum (0.98), thus, it takes precisely 43 days to revert back to half of its mean, which is greater than LSE- 25 and ISE-10 indices. On the contrary, the ISE-10 index has the lowest sum amongst the other two indices i.e. 0.72 , therefore, showing that returns of ISE-10 index revert back to half the value within 2 days that representing the highest speed of mean reversion.

Lastly, the LSE-25 index with a sum of 0.97 shows that its returns revert back to half of mean value within 25 days. This indicates that investors at ISE-10 index should open a position at 0 and close it after the 4 th day, then again open a position at 8 th and then close it on the 16th day. The reason that the closing position is taken 4 rather than 2 is half-life represented days the returns took to revert back to half of mean value. Thus, the half-life of 2 shows that it took 4 days for returns of the ISE-10 index to revert back to its mean value. On the contrary, for KSE-100 index the investor should open at 0 and close after 86 days. However, for LSE-25 index the investor should open for 0 and close position at 50th day.

Among the three indices, ISE-10 has the fastest mean reversion among them all. Thus, indicating for short-term investors, and it is better to invest in the ISE-10 index, whereas, for long-term investors KSE-100 index is better. On the other hand, as slow mean reversion means higher volatility, thus, if an investor is looking to gain higher returns and is ready to bear the risk of time then he should invest in KSE-100 index.

Table 5. Speed of Mean Reversion in the Stock Indices (source: authors' estimation)

\begin{tabular}{|l|c|c|}
\hline \multicolumn{1}{|c|}{ INDEX } & $\alpha+\beta$ & Half Life \\
\hline KSE-100 Index & 0.983866 & 43 Days \\
\hline LSE-25 Index & 0.972187 & 25 Days \\
\hline ISE-10 Index & 0.720937 & 2 Days \\
\hline
\end{tabular}

Table 6. Hypotheses tests summary (source: authors' estimation)

\begin{tabular}{|l|l|c|l|}
\hline \multicolumn{1}{|c|}{ Null Hypotheses } & Model & Sig & \multicolumn{1}{c|}{ Result } \\
\hline $\begin{array}{l}\text { The stock returns of KSE 100, LSE 25 } \\
\text { and ISE 10 index exhibit ARCH effect. }\end{array}$ & ARCH & 0.00000 & $\begin{array}{l}\text { Reject } \mathrm{H}_{1} \text {, thus concluded the } \\
\text { significance of ARCH effect }\end{array}$ \\
\hline $\begin{array}{l}\text { The stock returns of KSE 100, LSE 25 } \\
\text { and ISE 10 index exhibit ARCH effect. }\end{array}$ & GARCH & 0.00000 & $\begin{array}{l}\text { Reject } \mathrm{H}_{2} \text {, thus concluded the } \\
\text { significance of GARCH effect }\end{array}$ \\
\hline $\begin{array}{l}\text { The stock returns of KSE 100, LSE 25 } \\
\text { and ISE 10 index observe the mean } \\
\text { reversion process }\end{array}$ & $\begin{array}{l}\text { Sum of ARCH \& GARCH } \\
\text { Coefficients } \alpha+\beta<1\end{array}$ & $\begin{array}{l}\text { Support the null hypothesis } \\
\mathrm{H}_{3}\end{array}$ \\
\hline
\end{tabular}


Hypotheses summary. Table 6 depicted the summary of the hypotheses, which showed that our two developed null hypotheses are statistically significant and both ARCH and GARCH have significant effects because of $\mathrm{p}<0.01$ for both models. Moreover, the third hypothesis also supports our null hypothesis that all three stock markets indices have observed mean reversion process because the sum of coefficients of ARCH and GARCH is less than one $(\alpha+\beta<1)$.

\section{Discussions, conclusion and recommendations}

Discussions and conclusion. The study was conducted to determine the existence of mean reversion in stock markets indices of Pakistan. Further, to measure and compare the speed of mean reversion of Pakistani stock markets indices as well. The results of the study indicate that the three stock market indices of Pakistan that include KSE-100 index, LSE-25 index, and ISE-10 index show significant mean reversion process. This means that the returns of the three indices revert back to their previous value after a certain period of time. Therefore, enabling investors to forecast future returns on the basis of their historical value helping them in earning above average returns. Thus, supporting the studies of Chen and Hsu (2016), Vveinhardt et al. (2016), Chaves and Viswanathan (2016), Lal et al. (2016), Chaudhuri and Wu (2003), Riaz (2014), Poterba and Summers (1987), Malliaropulos and Priestley (1996), Mustafa and Ahmed (2013), Balvers et al. (2000) etc. who also found the existence of mean reversion in different stock indices of the world.

Further, to satisfy the second objective of the study, the speed of mean reversion of the three stock markets indices was determined through the Half-life method. Results of the study show that the returns of Karachi stock index revert back to half of its previous value after 43 days, whereas, for the LSE-25 index and ISE index this reversion take back after 25 days and 2 days respectively. This indicates that the KSE-100 index has the slowest speed of mean reversion as compared to the other two markets; the ISE-10 index has the fastest mean reversion. Thus, indicating that for a short-term investment, it is better to invest in the ISE-10 index as compared to KSE-100 index and LSE-25 index. On the contrary, for the long-term investors, it is better to invest in KSE-100 index. However, greater half-life or slow mean reversion means higher volatility (e.g., Poon 2005; Summers 1986; etc.). Thus, if the investors are ready to bear the risk of time then they should invest in KSE-100 index. As longer half-life indicate that, it is both time consuming and risky act to invest in that stock, but in turns, it helps to earn higher profit also.

Recommendations. The study identified the presence and speed of mean reversion of the stock markets indices of Pakistan, therefore, following recommendations have been proposed on the basis of results.

Firstly, the existence of mean reversion helps investors in the choice of strategy. For instance, in the case of mean reversion contrarian strategy could be used, which causes the investor to move against the crowd such as buying cheap stocks when everyone is selling them and selling them at a higher price when they are at peak. Apart from contrarian strategy, statistical arbitrage strategy could also be used. In the adoption of this strategy the investors purchase or sell shares on the basis of their relationship with each other. Thus, keeping these 
strategies of mean reversion an investor can prepare a portfolio. For example, the stocks could be grouped into the best and worst performing stocks (Bhave, Libertini 2013).

Secondly, the study through determination of the speed of mean reversion in term of halflife enables the investors to determine the period to which they should hold one stock and thus exit. For instance, a half-life of 43 days of KSE-100 index implies that an investor should exit from a position at the $86^{\text {th }}$ day. Similarly, as for LSE-25 index, the investor should exit from the trade at the 50th Day. Lastly, for ISE-10 index investor should exit from the trade at 4 th day. Further, the determination of mean reversion leads to the conclusion that an investor seeking a long-term investment such as retired individual should invest in KSE-100 index to gain higher return over a long period of time. On the other hand, an investor seeking a short-term investment such as speculators should invest ISE-10 index to gain higher returns in a short period of time.

Lastly, the existence of mean reversion also enables one to predict the future returns. Explaining the mean reversion role in forecasting mean reversion can be looked as one showing extreme reversion values or outliers that are occurring across the time period. Now, if a larger time period is related with outlier, the outlier shows the larger reversion. This further is resulting in a larger breakout, which leads to larger investment opportunity for the investor. Therefore, indicating that an investor should lighten up such stock in his/her portfolio. Similarly, if one stock has been giving below average returns than one by forecasting above average returns can change their portfolio by the inclusion of such stocks (Spierdijk, Bikker 2012).

\section{Limitations and delimitations}

However, there are certain limitation and delimitations of the study where the scope of the study ends. Firstly, it includes ignorance of asset markets. Secondly, as stock market indices of Pakistan particularly KSE-100 index, LSE-25 and ISE-10 indices are the focused while studying mean reversion. Thus, results could not be generalized to any other stock indices of any other geographical area.

The results of developed markets could be dissimilar because of intense globalization feature, thus, these markets are less volatile as compared to the Pakistani stock markets or any other emerging or frontier markets of the world. Another important aspect of future research could be the comparison of Pakistani markets with other emerging and developed stock markets of the world.

Lastly, the study fails to include the role of a structural break before testing for mean reversion; thus, the future research could be conducted by incorporating the structural breaks in considered time period. In addition, as the GARCH model has its limitation, such as, GARCH assumes that only magnitude of returns determines volatility, whereas the volatility can be determined by both magnitude and direction of returns. In other words GARCH assumes impact of negative shock on volatility is greater than the positive shocks. Secondly, although GARCH model considers conditional volatility but ignores the leverage effect, therefore, the same research could be conducted by applying different extensions of GARCH models that can overcome the above-specified limitations (Brooks 2008). 


\section{References}

Annaert, J.; Hyfte, W. V. 2005. Long run mean reversion for the Brussels stock exchange: evidence for the 19th Century, SSRN Electronic Journal (April).

Bali, T. G.; Demirtas, K. O. 2008. Testing mean reversion in financial market volatility: evidence from S\&P 500 Index futures, The Journal of Futures Markets 28(1): 1-33. https://doi.org/10.1002/fut.20273

Balsara, N. J.; Chen, G.; Zheng, L. 2007. The Chinese stock market: an examination of the random walk model and technical trading rules, Quarterly Journal of Business and Economics 46(2): 43-63.

Balvers, R.; Wu, Y.; Gilliland, E. 2000. Mean reversion across national stock markets and parametric contrarian investment strategies, The Journal of Finance 55(2): 745-772.

https://doi.org/10.1111/0022-1082.00225

Bhave, A.; Libertini, N. J. 2013. A study of short term mean reversion in equities. 361 CAPITAL [online], [cited 12 March 2015]. Available from Internet: http://www.361capital.com/wp-content/uploads/2013/10/361_Capital_Study_Short_Term_Mean_Reversion_Equities.pdf

Bollerslev, T. 1986. Generalized autoregressive conditional heteroskedasticity, Journal of Econometrics 31(3): 307-327. https://doi.org/10.1016/0304-4076(86)90063-1

Borges, M. R. 2011. Random walk tests for the Lisbon stock market, Applied Economics 43(5): 631-639. https://doi.org/10.1080/00036840802584935

Boussaidi, R.; Kouki, M. 2015. Stock price mean reversion to fundamentals and long-run return predictability in the Tunisian Stock Market, International Journal of Business and Management 10(8). https://doi.org/10.5539/ijbm.v10n8p183

Brooks, C. 2008. Introductory econometric for finance. Cambridge University Press. https://doi.org/10.1017/CBO9780511841644

Chaudhuri, K.; Wu, Y. 2003. Mean reversion in stock prices: evidence from emerging markets, Managerial Finance 29(10): 22-37. https://doi.org/10.1108/03074350310768490

Chaves, D. B.; Viswanathan, V. 2016. Momentum and mean-reversion in commodity spot and futures markets, Journal of Commodity Markets 3(1): 39-53. https://doi.org/10.1016/j.jcomm.2016.08.001

Chen, Q.; Jiang, Y.; Li, Y. 2012. The state of the market and the contrarian strategy: evidence from China's stock market, Journal of Chinese Economic and Business Studies 10(1): 89-108. https://doi.org/10.1080/14765284.2012.638473

Chen, S-W.; Hsu, C-S. 2016. Threshold, smooth transition and mean reversion in inflation: new evidence from European countries, Economic Modelling 53: 23-36. https://doi.org/10.1016/j.econmod.2015.11.006

Chi, Z.; Dong, F.; Wong, H. Y. 2016. Option pricing with threshold mean reversion, Journal of Futures Markets 37(2): 107-137. https://doi.org/10.1002/fut.21795

DeBondt, W. F. M; Thaler, R. 1985. Does the stock market overreact, Journal of Finance 40(3): 793-805. https://doi.org/10.1111/j.1540-6261.1985.tb05004.x

Dickey, D. A.; Fuller, W. A. 1979. Distribution of estimators for autoregressive time series with a unit root, Journal of the American Statistical Association 74(366a): 427-431. https://doi.org/10.1080/01621459.1979.10482531

Dickey, D. A.; Fuller, W. A. 1981. Likelihood ratio statistics for autoregressive time series with a unit root, Econometrica 49(4): 1057-1072. https://doi.org/10.2307/1912517

Dupernex, S. 2007. Why might share prices follow a random walk?, Student Economic Review 21: 167-179, [online], [cited 18 March 2015]. Available from Internet: https://www.tcd.ie/Economics/ assets/pdf/SER/2007/Samuel_Dupernex.pdf

Engle, C.; Morris, C.S. 1991. Challenges to stock market efficiency: evidence from mean reversion studies, Economic Review [online], [cited 20 March 2015]. Available from Internet: http://www.kc.frb. org/PUBLICAT/ECONREV/econrevarchive/1991/3-4q91enge.pdf 
Engle, R. 2001. GARCH 101: the use of ARCH/GARCH models in applied econometrics, Journal of Econometric Perspectives 15(4): 157-168. https://doi.org/10.1257/jep.15.4.157

Fama, E. F.; French, K. R. 1988. Permanent and temporary components of stock prices, Journal of Political Economy 95(2): 246-273. https://doi.org/10.1086/261535

García, F.; González-Bueno, J. A.; Oliver, J. 2015. Mean-variance investment strategy applied in emerging financial markets: evidence from the Colombian stock market, Intellectual Economics 9(1): 22-29. https://doi.org/10.1016/j.intele.2015.09.003

Gimpel, H. 2007. Preferences in negotiations: the attachment effect. New York: Springer Science \& Business Media.

Goudarzi, H. 2013. Volatility mean reversion and stock market efficiency, Asian Economic and Financial Review 3(12): 1681-1692 [online], [cited 22 March 2015]. Available from Internet: http://www. aessweb.com/pdf-files/aefr\%203(12),\%201681-1692.pdf

Hakim, S.; Neaime, S. 2003. Mean-Reversion across mena stock markets: implications for portfolio allocations, International Journal of Business 8(3).

Hart, C. E.; Lence, S. H.; Hayes, D. J.; Jin, N. 2015. Price mean reversion, seasonality, and options markets, American Journal of Agricultural Economics 98(3): 707-725. https://doi.org/10.1093/ajae/aav045

Henderson, T. M. 2004. Fixed income strategy: a practitioner's guide to riding the curve. John Wiley \& Sons.

Hillebrand, E. 2003. Mean reversion model of financial markets. Bremen: University of Bremen.

Huggins, D.; Schaller, C. 2013. Fixed income relative value analysis: a practitioners guide to theory, tools and trades. John Wiley \& Sons Inc.

İzgi, B.; Duran, A. 2016. 3D extreme value analysis for stock return, interest rate and speed of mean reversion, Journal of Computational and Applied Mathematics 297: 51-64. https://doi.org/10.1016/j.cam.2015.10.009

Kim, C.-J.; Morley, J. C.; Nelson, C. R. 2001. Does an intertemporal tradeoff between risk and return explain mean reversion in stock prices?, Journal of Empirical Finance 403-426 [online], [cited 22 March 2015]. Available from Internet: http://research.economics.unsw.edu.au/jmorley/kmn01.pdf

Kim, M. J.; Nelson, C. R.; Startz, R. 1991. Mean reversion in stock prices? A reappraisal of empirical evidence, The Review of Economic Studies 58(3): 515-528 [online], [cited 23 March 2015]. Available from Internet: http://www.e-m-h.org/KiNS91.pdf

Kühnlenz, S. 2014. Economic bubbles: a story of new eras, emotional contagion and structural support. Anchor Academic Publishing.

Lal, I.; Mubeen, M.; Hussain, A.; Zubair, M. 2016. An empirical analysis of higher moment capital asset pricing model for Karachi Stock Exchange (KSE), Open Journal of Social Sciences 4(6): 53-60. https://doi.org/10.4236/jss.2016.46006

Lim, K. G. 2011. Financial valuation and econometrics. World Scientific. https://doi.org/10.1142/7782

Lo, A. W.; MacKinlay, A. C. 1988. Stock market prices do not follow random walk: evidence from a simple specification test, The Review of Financial Studies 1(1): 41-66. https://doi.org/10.1093/rfs/1.1.41

Lock, D. B. 2007. The Taiwan stock market does follow a random walk, Economics Bulletin 7(3): 1-8 [online], [cited 25 March 2015]. Available from Internet: http://www.accessecon.com/pubs/ EB/2007/Volume7/EB-07G00001A.pdf

Lubnau, T.; Todorova, N. 2015. Trading on mean-reversion in energy futures markets, Energy Economics 51: 312-319. https://doi.org/10.1016/j.eneco.2015.06.018

MacKinnon, J. G. 1996. Numerical distribution functions for unit root and cointegration, Journal of Applied Econometrics 11(6): 601-618. https://doi.org/10.1002/(SICI)1099-1255(199611)11:6<601::AIDJAE417>3.0.CO;2-T 
Malkiel, B. G. 2003. The efficient market hypothesisand its critics [online], [cited 26 March 2015]. Princeton University. Available from Internet: https://www.princeton.edu/ ceps/workingpapers/91malkiel. pdf.

Malliaropulos, D.; Priestley, R. 1996. Mean reversion in Southeast Asian stock markets, Journal of Empirical Finance 6(4): 355-384. https://doi.org/10.1016/S0927-5398(99)00010-9

Manzana, S. 2007. Nonlinear mean reversion in stock prices, Quantitative and Qualitative Analysis in Social Sciences 1(3): 1-20 [online], [cited 26 March 2015]. Available from Internet: http://qass.org. uk/2007/vol1_3/paper_1-manzan.pdf

Mtunya, A. P.; Ngare, P.; Nkansah-Gyekye, Y. 2016. On steady dividend payment under functional mean reversion speed, Journal of Mathematical Finance 6(3): 368-377. https://doi.org/10.4236/jmf.2016.63030

Mustafa, K.; Ahmed, R. 2013. The random walk model in the Karachi Stock Market: an empirical investigation, Journal of Economics and Sustainable Development 4(3): 262-278 [online], [cited 27 March 2015]. Available from Internet: http://www.academia.edu/4747822/The_Random_Walk_Model_in_ the_Karachi_Stock_Market_An_Empirical_Investigation

Narayan, P. K.; Narayan, S. 2007. Mean reversion in stock prices: new evidence from panel unit root tests, Studies in Economics and Finance 24(3): 233-244. https://doi.org/10.1108/10867370710817419

Narayan, P. K.; Smyth, R. 2006. Are OECD stock prices characterized by a random walk? Evidence from sequential trend break and panel data models, Applied Financial Economics 15(8): 547-556. https://doi.org/10.1080/0960310042000314223

Neaime, S. 2015. Are emerging MENA stock markets mean reverting?, A Monte Carlo simulation, Finance Research Letters 13: 74-80. https://doi.org/10.1016/j.frl.2015.03.001

Oikarinen, E.; Schindler, F. 2015. Momentum and mean reversion in regional housing markets: evidence from variance ratio tests, International Journal of Strategic Property Management 19(3): 220234. https://doi.org/10.3846/1648715X.2015.1031854

Okpara, G. C. 2010. Stock market prices and the random walk hypothesis: further evidence from Nigeria, Journal of Economics and International Finance 2(3): 49-57 [online], [cited 28 March 2015]. Available from Internet: https://www.researchgate.net/profile/Godwin_Okpara/publication/228614312_Stock_market_prices_and_the_random_walk_hypothesis_Further_evidence_ from_Nigeria/links/00b7d523409d4cbb17000000.pdf

Poon, S.-H. 2005. A practical guide to forecasting financial market volatility. John Wiley \& Sons.

Poshakwale, S. 2003. The random walk hypothesis in the emerging Indian Stock Market, Journal of Business Finance \& Accounting 29(9-10): 1275-1299.

Poterba, J. M.; Summers, L. H. 1987. Mean reversion in stock prices: evidence and implications [online], [cited 29 March 2015]. The National Bureau of Economic Research. Available from Internet: http:// dspace.mit.edu/bitstream/handle/1721/63837/meanreversionins00pote.pdf?sequence $=1$

Riaz, T. 2014. Mean reversion in stock prices: evidence from Karachi Stock Exchange, World Academy of Science, Engineering and Technology, International Science Index, Economics and Financial Engineering 2(2): 657.

Saeedi, A.; Miraskari, S. R.; Ara, M. S. 2012. The investigation of efficient market hypothesis: evidence from an emerging market, The Asian Business and Management Conference, 363-377. Osaka: The international Academic Forum.

Serletis, A.; Rosenberg, A. A. 2009. Mean reversion in the US stock market, Chaos, Solitons \& Fractals 40(4): 2007-2015. https://doi.org/10.1016/j.chaos.2007.09.085

Shaffer, D. S. 2010. Profiting in economic storms: a historic guide to surviving depression, deflation, hyperinflation, and market bubbles. John Wiley \& Sons. 
Spierdijk, L.; Bikker, J. 2012. Mean reversion in stock prices: implication for long term investors [online], [cited 30 March 2015]. Amsterdam: De Nederlandsche Bank. Available from Internet: http://www. dnb.nl/en/binaries/Working\%20Paper\%20343_tcm47-271856.pdf

Summers, L. H. 1986. Does the stock market rationally relfect fundamental values?, The Journal of Finance 41(3): 591-601. https://doi.org/10.1111/j.1540-6261.1986.tb04519.x

Tie, J.; Zhang, Q. 2016. An optimal mean-reversion trading rule under a Markov chain model, Mathematical Control and Related Fields 6(3): 467-488. https://doi.org/10.3934/mcrf.2016012

Tsekrekos, A. E.; Yannacopoulos, A. N. 2016. Optimal switching decisions under stochastic volatility with fast mean reversion, European Journal of Operational Research 251(1): 148-157. https://doi.org/10.1016/j.ejor.2015.12.011

Urrutia, J. L. 1995. Tests of random walk and market efficiency for Latin American emerging equity markets, Journal of Financial Research 18(3): 299-309. https://doi.org/10.1111/j.1475-6803.1995.tb00568.x

Vveinhardt, J.; Streimikiene, D.; Ahmed, R. R.; Ahmad, N.; Rehman, A. 2016. Mean reversion: an investigation from Karachi Stock Exchange Sectors, Technological and Economic Development of Economy 22(4): 493-511.

Wang, J.; Zhang, D.; Zhang, J. 2015. Mean reversion in stock prices of seven Asian stock markets: unit root test and stationary test with Fourier functions, International Review of Economics \& Finance 37: 157-164. https://doi.org/10.1016/j.iref.2014.11.020

Yilanci, V. 2012. Mean reversion in stock prices of G7 countries: evidence from panel SURADF and panel SURKSS tests, Actual Problems of Economics: 380-385 [online], [cited 30 March 2015]. Available from Internet: http://irbis-nbuv.gov.ua/cgibin/irbis_nbuv/cgiirbis_64.exe?C21COM=2 $\& I 21 D B N=U J R N \& P 21 D B N=U J R N \& I M A G E \_F I L E \_D O W N L O A D=1 \& I m a g e \_f i l e \_n a m e=P D F /$ ape_2012_5_48.pdf

Zakamulin, V. 2016. Secular mean reversion and long-run predictability of the stock market, Bulletin of Economic Research 69(4): E66-E93. https://doi.org/10.1111/boer.12105 